\title{
Explicit and implicit cannabis associations in patients with recent-onset schizophrenia and healthy controls
}

Citation for published version (APA):

Dekker, N., Smeerdijk, A., Wiers, R. W. H. J., van Gelder, G., Houben, K. M. P. I., Schippers, G., Linszen, D., \& de Haan, L. (2010). Explicit and implicit cannabis associations in patients with recent-onset schizophrenia and healthy controls. Psychological Medicine, 40, 1325-1336.

https://doi.org/10.1017/S0033291709991814

Document status and date:

Published: 01/01/2010

DOI:

10.1017/S0033291709991814

Document Version:

Publisher's PDF, also known as Version of record

Document license:

Taverne

Please check the document version of this publication:

- A submitted manuscript is the version of the article upon submission and before peer-review. There can be important differences between the submitted version and the official published version of record.

People interested in the research are advised to contact the author for the final version of the publication, or visit the DOI to the publisher's website.

- The final author version and the galley proof are versions of the publication after peer review.

- The final published version features the final layout of the paper including the volume, issue and page numbers.

Link to publication

\footnotetext{
General rights rights.

- You may freely distribute the URL identifying the publication in the public portal. please follow below link for the End User Agreement:

www.umlib.nl/taverne-license

Take down policy

If you believe that this document breaches copyright please contact us at:

repository@maastrichtuniversity.nl

providing details and we will investigate your claim.
}

Copyright and moral rights for the publications made accessible in the public portal are retained by the authors and/or other copyright owners and it is a condition of accessing publications that users recognise and abide by the legal requirements associated with these

- Users may download and print one copy of any publication from the public portal for the purpose of private study or research.

- You may not further distribute the material or use it for any profit-making activity or commercial gain

If the publication is distributed under the terms of Article $25 \mathrm{fa}$ of the Dutch Copyright Act, indicated by the "Taverne" license above, 


\title{
Implicit and explicit affective associations towards cannabis use in patients with recent-onset schizophrenia and healthy controls
}

\author{
N. Dekker ${ }^{*}$, A. M. Smeerdijk ${ }^{1}$, R. W. Wiers ${ }^{2}$, J. H. Duits ${ }^{1}$, G. van Gelder ${ }^{1}$, K. Houben $^{3}$, G. Schippers ${ }^{1,4}$, \\ D. H. Linszen ${ }^{1}$ and L. de Haan ${ }^{1}$ \\ ${ }^{1}$ Department of Psychiatry, Academic Medical Centre, Amsterdam, The Netherlands \\ ${ }^{2}$ Department of Psychology, University of Amsterdam, Amsterdam, The Netherlands \\ ${ }^{3}$ Faculty of Psychology, Department of Experimental Psychology, Maastricht University, Maastricht, The Netherlands \\ ${ }^{4}$ Amsterdam Institute for Addiction Research, Amsterdam, The Netherlands
}

Background. Cannabis use is common in patients with recent-onset schizophrenia and this is associated with poor disease outcome. More insight in the cognitive-motivational processes related to cannabis use in schizophrenia may inform treatment strategies. The present study is the first known to compare implicit and explicit cannabis associations in individuals with and without psychotic disorder.

\begin{abstract}
Method. Participants consisted of 70 patients with recent-onset psychotic disorder and 61 healthy controls with various levels of cannabis use. Three Single-Category Implicit Association Tests (SC-IAT) were used to assess 'relaxed', 'active' and 'negative' implicit associations towards cannabis use. Explicit expectancies of cannabis use were assessed with a questionnaire using the same words as the SC-IAT.

Results. There were no differences in implicit associations between patients and controls; however, patients scored significantly higher on explicit negative affect expectancies than controls. Both groups demonstrated strong negative implicit associations towards cannabis use. Explicit relaxed expectancies were the strongest predictors of cannabis use and craving. There was a trend for implicit active associations to predict craving.

Conclusions. The findings indicate that patients suffering from schizophrenia have associations towards cannabis similar to controls, but they have stronger negative explicit cannabis associations. The strong negative implicit associations towards cannabis could imply that users of cannabis engage in a behaviour they do not implicitly like. Explicit relaxing expectancies of cannabis might be an important mediator in the continuation of cannabis use in patients and controls.
\end{abstract}

Received 17 December 2008; Revised 25 September 2009; Accepted 6 October 2009; First published online 17 November 2009

Key words: Cannabis, craving, Implicit Association Task, psychosis, schizophrenia.

\section{Introduction}

Cannabis is commonly used in patients with first episode schizophrenia (Hambrecht \& Hafner, 1996; Cantwell et al. 1999; Van Mastrigt et al. 2004; Barnes et al. 2006; Barnett et al. 2007). Prevalence rates for current cannabis use disorder in first episode psychosis in dual diagnosis studies range from 30\% to 63\% (Van Mastrigt et al. 2004; Wade et al. 2006; Addington \& Addington, 2007; Barnett et al. 2007). Several studies demonstrate that co-morbid cannabis abuse is associated with increased relapse or rehospitalization and decreased treatment adherence (Linszen et al. 1994; Zammit et al. 2008).

* Address for correspondence: Dr N. Dekker, Department of Psychiatry, Academic Medical Centre, University of Amsterdam, Meibergdreef 5, 1105 AZ, Amsterdam, The Netherlands.

(Email : nienke.dekker@amc.uva.nl)
If we obtain more insight into the cognitivemotivational processes related to cannabis use in patients suffering from schizophrenia, we may be able to develop effective treatment strategies. Several studies have tried to unravel the cognitivemotivational construct related to cannabis use in patients with psychotic disorder by assessing selfreported motives for cannabis use, self-reported effects of cannabis use and effect expectancies of cannabis use (e.g. Dixon et al. 1990; Mueser et al. 1995; Addington \& Duchak, 1997; Fowler et al. 1998; Spencer et al. 2002; Green et al. 2004; Schofield et al. 2006; reviewed in Dekker et al. 2009; Hides et al. 2008). Overall, these studies find that patients with schizophrenia use cannabis to enhance positive affect, to relieve dysphoria, to socialize with peers and, to a lesser extent, to relieve psychotic symptoms or side-effects of medication. Further, these studies find that patients not 
only report positive effects, but also negative effects of cannabis use, such as cognitive impairment. All of the above-mentioned studies relied on self-report from the patient. Self-report measures, however, have been criticized because of their susceptibility to selfpresentation biases (e.g. Holtgraves, 2004) and the possibility that cognitive processes mediating substance abuse are not accessible through introspection (Stacy, 1997; McCusker, 2001). For these reasons, Greenwald \& Banaji (1995) proposed the use of more implicit (indirect) measures in addition to the use of explicit measures, which may tap different underlying cognitive-motivational processes (Stacy, 1997; Wilson et al. 2000). Moreover, several studies have found that implicit and explicit alcohol- and cannabis-related cognitions predict unique variance in alcohol and cannabis use (Stacy, 1997; Wiers et al. 2002, 2005; Ames et al. 2007).

Implicit measures are intended to assess relatively automatic associations that are difficult to gauge with explicit self-report measures. In general, these measures intend to make a participant react fast and spontaneously without self-reflection or introspection. Explicit measures assess cognitions that are related to slower deliberate processes that may inhibit more automatic, impulsive thinking and behaviour (Greenwald \& Banaji, 1995; Kahneman, 2003). A test often used to assess alcohol or drug-related memory associations is the Implicit Association Test (IAT; Greenwald et al. 1998). The IAT assesses the relative strength of associations indirectly, without asking people to reflect and report motivations for their behaviour. It is a computerized categorization task based on the principle that people find it easier to categorize stimuli together if those stimuli are strongly associated rather than if the stimuli are not associated. During the past decade, varieties of the IAT have been applied in the field of addiction research (e.g. Wiers et al. 2002, 2005, 2007a,b; De Houwer et al. 2004). To date, two studies have used a cannabis-IAT to assess implicit associations towards cannabis. Field et al. (2004) found more negative associations for marijuana-related words in non-users compared with users, which could be interpreted as indicating that non-users associated unpleasant words more strongly with cannabis compared with users. No significant differences were found between non-users and users for positive marijuana associations. Ames et al. (2007) reported that implicit excitement associations towards cannabis predicted cannabis use when controlled for explicit cognition measures. Determining the predictive value of implicit measures after controlling for explicit measures is often used to determine the unique predictive power of implicit measures beyond commonly used explicit questionnaires. Implicit associations towards cannabis have not been investigated in patients with schizophrenia or related disorders. Also, few studies have been reported on craving for cannabis in psychotic disorder, although craving is regarded as a central phenomenon in drug dependence (Robinson \& Berridge, 1993; Franken, 2003).

In the current study, one of our questions was whether patients with recent-onset schizophrenia and healthy controls differ on implicit and explicit cannabis-related cognitions. Second, we were interested in the extent to which explicit and implicit cannabisrelated cognitions predict craving and cannabis use. We included participants with varying levels of cannabis exposure in order to determine whether the differences between patients and controls would depend on their cannabis use status and also for a proper variance in cannabis use patterns and craving levels in the prediction model.

Our study may contribute to more insight in the underlying processes in addictive behaviour in cannabis-using patients suffering from schizophrenia.

\section{Method \\ Participants}

We included male in- and out-patients from the Adolescent Clinic of the Psychiatric Department of the Academic Medical Centre in Amsterdam. This clinic specializes in the treatment of young patients with schizophrenia spectrum disorders. In general, two-thirds of patients are admitted for psychosis for the first or second time (Dekker et al. 2008) and most of the patients use antipsychotic medication (De Haan et al. 2003).

Patients were included in the study if they had a diagnosis of schizophrenia or related disorder (schizoaffective disorder, schizophreniform disorder or psychosis not otherwise specified), according to DSM-IV criteria (APA, 1994) and were aged between 16 and 30 years. Other inclusion criteria were that patients should be able and willing to give written informed consent and be able to understand, speak and read Dutch. Exclusion criteria were diagnosis of a primary alcohol- or drug-related psychosis, a demonstrable brain or neurological or endocrine disease or mental retardation. Male healthy controls were recruited from the community and matched with regard to age and level of education. In a first recruitment phase, a larger proportion of controls had never used cannabis compared with patients. To ensure comparable levels of cannabis use in both participant groups, we later recruited controls more strictly on the basis of their level of cannabis use. Only males were included. Males generally have an earlier age at onset of 
psychosis, more often need intensive psychiatric care and more often use cannabis compared with females. Therefore, males are over-represented at our clinic. Exclusion criteria for healthy controls were a history of psychotic disorder or a first-degree family member with a history of psychotic disorder. After complete description of the study, written informed consent was obtained from all participants. The study was approved by the human subject review board of the Academic Medical Centre, Amsterdam.

\section{Materials and measures}

Drug use

Drug use was assessed with the Composite International Diagnostic Interview (CIDI; WHO, 1994) section L. Participants with lifetime cannabis use of five times or less were considered to be 'non-users'. Participants who had used cannabis more than five times in their lifetime were subdivided into 'past users' (those who had used cannabis more than 12 months ago) and 'recent users' (those who had used cannabis in the recent 12 months). Recent use was further subdivided into 'infrequent use' (less than weekly use in the past year) and 'frequent use' (daily or weekly use in the past year). In 'recent users', we estimated the total amount of cannabis joints used in the past year by multiplying total weeks of cannabis use in the past year by average amount of cannabis joints used per week in the period that cannabis was used. Although there is a variety in percentage of delta-9-tetrahydrocannabinol $\left(\Delta^{9}\right.$-THC) and cannabidiol (CBD) in different cannabis products (Niesink et al. 2007), one cannabis joint was considered to contain $0.5 \mathrm{~g}$ of cannabis product (e.g. hash, weed, etc.).

\section{Craving for cannabis}

The Obsessive Compulsive Drug Use Scale (Franken et al. 2002) was used in past and recent cannabis users to measure craving for cannabis in the past 7 days. It is a self-rating scale consisting of 12 items with a 5-point, Likert-type rating that measures drug craving in the past 7 days. The 12 items were summed to create a total craving score (Cronbach's $\alpha=0.85$ ).

\section{Implicit association test}

Implicit affective associations towards cannabis were assessed with three unipolar Single Category Implicit Association Tests (SC-IATs; Karpinski \& Steinman, 2006). Each SC-IAT measured a different affective association towards the use of cannabis: 'active' for positive arousal; 'negative' for negative affect; 'relaxed' for positive sedation. Other IAT studies in addiction research have also used these subscales (e.g. Ames et al. 2007; Wiers et al. 2007b), because they represent the three main types of expectancies (Goldman \& Darkes, 2004; Wiers, 2008). Each affective category was compared with a neutral category labelled 'neutral'. In the SC-IAT, participants have to categorize words as quickly as possible into different categories by pressing a left or right response button. Each SC-IAT consisted of four phases that came in a fixed order (see Table 1). For someone who has a very strong association between cannabis and one of the affective categories (e.g. active), the combination block where cannabis and active are on the same side will be significantly easier (and thus faster) to perform than the reversed combination block, where cannabis and active are on different sides. Each combination phase consisted of 40 words. The three SC-IATs were presented in a fixed order. The IAT tasks were programmed in INQUISIT 2.0 (Millisecond Software, USA). Stimulus words were presented in blue font (34-point) in the middle of the screen. The affective label words were always presented at the top of the screen, appropriately positioned on the left or the right side of the screen, depending on the required response (as in Greenwald et al. 1998). Feedback appeared in green letters (34-point) below the stimuli words: in the case of a wrong response, the words 'try again' appeared on the screen. The words used (see Appendix) were matched on number of letters, syllables, familiarity and on valence and arousal values. The valence and arousal values of stimulus words were matched on group level (positive arousal, positive sedation, negative and neutral words) by using student word ratings.

As main outcome measure for the IAT, we chose one of the recently recommended new ' $D$-algorithms' as main reaction time measure (D2SD; Greenwald et al. 2003). In this algorithm all trials (including the practise phases) are included, an error penalty to the reaction times on erroneous responses is given and the outcome is divided by a personalized standard deviation of the combination phases (so the measure is not influenced by differences in response speed between participants, which is optimal for comparison between clinical and non-clinical groups).

\section{Expectancy questionnaire}

The explicit cannabis expectancy measure was a questionnaire with 18 unipolar items, each consisting of a statement on using cannabis and an affective outcome (for example: 'Smoking cannabis makes me relaxed'). Participants indicated the extent to which they agreed or disagreed with each item on an unmarked visual analogue scale (VAS). The questionnaire consisted of an active (positive-arousal) scale, a negative 
Table 1. Schematic overview of the block sequence in the active, relaxed and negative Single Category - Implicit Association Tests (SC-IATs)

\begin{tabular}{|l|l|l|l|l|}
\hline & Block 1 phase & $\begin{array}{l}\text { Block 2 } \\
\text { Combination phase }\end{array}$ & $\begin{array}{l}\text { Block 3 } \\
\text { Reversed practise } \\
\text { phase }\end{array}$ & $\begin{array}{l}\text { Block 4 } \\
\text { Reversed combination } \\
\text { phase }\end{array}$ \\
\hline Active SC-IAT & active neutral & $\begin{array}{l}\text { active neutral } \\
\text { cannabis }\end{array}$ & neutral active & $\begin{array}{l}\text { neutral } \\
\text { cannabis }\end{array}$ \\
\hline Relaxed SC-IAT & relaxed neutral & $\begin{array}{l}\text { relaxed neutral } \\
\text { cannabis }\end{array}$ & neutral relaxed & $\begin{array}{l}\text { neutral } \\
\text { cannabis }\end{array}$ \\
\hline Negative SC-IAT & negative neutral & $\begin{array}{l}\text { negative neutral } \\
\text { cannabis }\end{array}$ & neutral negative & $\begin{array}{l}\text { neutral negative } \\
\text { cannabis }\end{array}$ \\
\hline
\end{tabular}

The following explanation is for the active SC-IAT (for an explanation of the relaxed SC-IAT, replace active with relaxed, for an explanation of the negative SC-IAT, replace active with negative). During the practise phase (block 1), participants press the left key when the stimulus word that comes up in the middle of the screen is an active word (e.g. energetic) and press the right key when the stimulus word is neutral (e.g. standard). In the combination task (block 2), participants press the left key when the stimulus word is an active or a cannabis word (e.g. hash) and press the right key when the stimulus word is neutral. During the reversed practise phase (block 3), participants press the left key when the stimulus word is neutral and press the right key when the target word is an active word. During the reversed combination task, participants press the left key when the stimulus word is a neutral or a cannabis word and press the right key when the stimulus word is an active word. Note that during the combination phase and the reversed combination phase, cannabis is paired with one of the affective categories (e.g. active) or the neutral category respectively. The difference score between the reaction times of these two combined blocks is the so-called IAT-effect and gives an indication of strength of the association between the target (e.g. cannabis) and the affective category (e.g. active) (Greenwald et al. 1998).

outcome scale and a relaxed (positive-sedation) scale, with the same affective words as used in the implicit test. Internal consistencies were as follows: VAS active 0.81 ; VAS relaxed 0.86 ; VAS negative 0.82 .

\section{Procedure}

After signing the informed consent form, drug use was assessed with the CIDI. Next, participants performed the cannabis SC-IATs on a computer and, subsequently, the explicit expectancy questionnaire and craving questionnaire were filled out.

\section{Data screening}

IAT effects were calculated in such a way that higher IAT scores reflected a stronger association between cannabis and the affective dimension. The total amount of cannabis joints used in the past year scores and total craving scores were positively skewed and $\log _{10}$ transformations addressed this problem satisfactorily. For two participants, the score of total cannabis joints used in the past year was missing.

\section{Statistical analysis}

For comparisons between patients and controls on explicit and implicit measures, we used multivariate analysis of variance (MANOVA) with the three explicit variables and three implicit variables as dependent variables. In order to assess the relative contribution to multivariate differences, a discriminant analysis was performed that focused on the structure coefficients (Huberty \& Morris, 1989).

In the comparisons between patients and controls, we first took all participants into account, second only past and recent cannabis users, third only recent infrequent and frequent users and last only recent frequent cannabis users.

We used multiple hierarchical regression analysis to evaluate the predictive utility of the explicit and implicit measures for craving and cannabis use (total cannabis joints used in past year). In the regression models we entered participant group into step 1 and highest achieved level of education into step 2 of the regression equation as background variables. In step 3 , we added measures of explicit expectancies and, finally, in step 4 we added measures of implicit associations. The implicit measures were entered last to evaluate their predictive value added, above and beyond that of the other (explicit) variables.

The $\alpha$ level was set at 0.05 for all analyses to ensure an optimal trade-off between completeness (not leaving out possible interesting effects) and correctness (restricting type II error) given the exploratory nature of the data. 
Table 2. Participant characteristics

\begin{tabular}{|c|c|c|c|c|c|c|}
\hline & $\begin{array}{l}\text { Patients } \\
(n=70)\end{array}$ & $\begin{array}{l}\text { Controls } \\
(n=61)\end{array}$ & & $\chi^{2}$ & $\mathrm{df}$ & $p$ value \\
\hline Age, mean (S.D.), range & $\begin{array}{l}23.0(3.5) \\
17.2-30.1\end{array}$ & $\begin{array}{l}22.8(3.9) \\
16.2-31.8\end{array}$ & $F=0.25$ & & 129 & 0.79 \\
\hline Male, $n(\%)$ & $70(100)$ & $61(100)$ & & & & \\
\hline \multicolumn{7}{|l|}{ Diagnosis } \\
\hline Schizophrenia, $n(\%)$ & $50(71.4)$ & & & & & \\
\hline Schizoaffective disorder, $n(\%)$ & $12(17.1)$ & & & & & \\
\hline Schizophreniform disorder, $n(\%)$ & $4(5.7)$ & & & & & \\
\hline Psychosis NOS, $n(\%)$ & $4(5.7)$ & & & & & \\
\hline \multicolumn{7}{|l|}{ Education: highest achieved level ${ }^{\mathrm{a}}$} \\
\hline 1 & $38(54.3 \%)$ & $28(45.9 \%)$ & & 0.92 & 1 & 0.34 \\
\hline 2 & $16(22.9 \%)$ & $14(23.0 \%)$ & & 0.00 & 1 & 0.99 \\
\hline 3 & $16(22.9 \%)$ & $19(31.1 \%)$ & & 1.14 & 1 & 0.29 \\
\hline $\begin{array}{l}\text { Age at onset of cannabis use, } \\
\text { mean (s.D.), range }\end{array}$ & $\begin{array}{l}15.4(2.6), \\
11-23\end{array}$ & $\begin{array}{l}15.0(1.4) \\
12-20\end{array}$ & $Z=-0.17$ & & & 0.87 \\
\hline \multicolumn{7}{|l|}{ Cannabis use } \\
\hline Non-use & $9(12.9 \%)$ & $15(24.6 \%)$ & & 3.00 & 1 & 0.08 \\
\hline Past use only ${ }^{\mathrm{b}}$ & $15(21.4 \%)$ & $6(9.8 \%)$ & & 3.25 & 1 & 0.07 \\
\hline Recent infrequent use ${ }^{c}$ & $10(14.3 \%)$ & $13(21.3 \%)$ & & 1.11 & 1 & 0.29 \\
\hline Recent frequent use $^{\mathrm{d}}$ & $36(51.4 \%)$ & $27(44.2 \%)$ & & 0.67 & 1 & 0.41 \\
\hline $\begin{array}{l}\text { Total cannabis joints in past yeare, } \\
\text { mean (s.D.), range }\end{array}$ & $\begin{array}{l}461.9(611) \\
1-3388\end{array}$ & $\begin{array}{l}339.9(518), \\
1-2548\end{array}$ & $Z=-1.06$ & & & 0.29 \\
\hline $\begin{array}{l}\text { Total craving for cannabis score }{ }^{f}, \\
\text { mean (s.D.), range }\end{array}$ & $\begin{array}{l}20.8(8.0) \\
12-47\end{array}$ & $\begin{array}{l}20.5(6.5) \\
12-36\end{array}$ & $Z=-0.29$ & & & 0.77 \\
\hline $\begin{array}{l}\text { Cannabis use disorder in past year, } \\
n(\%)\end{array}$ & $33(47.1 \%)$ & $28(45.9 \%)$ & & 0.021 & 1 & 0.89 \\
\hline
\end{tabular}

df, Degrees of freedom; S.D., standard deviation; $Z, Z$ score of Mann-Whitney $U$ test.

a 1 , Lower secondary professional education/intermediate vocational education; 2 , higher general secondary education/higher vocational education; 3 , pre-university education/university.

${ }^{\mathrm{b}}$ Cannabis use more than 12 months ago.

${ }^{\mathrm{c}}$ Less than weekly use in past 12 months.

${ }^{\mathrm{d}}$ Weekly or daily use in past 12 months.

e In recent (past 12 months) cannabis users.

${ }^{\mathrm{f}}$ In past and recent cannabis users.

\section{Results}

\section{Sample characteristics}

Table 2 gives the sample characteristics. The patient group and the control group did not significantly differ in age, level of education, cannabis use (i.e. nonuse, past use only, recent infrequent use and recent frequent use), total cannabis joints used in the past year, craving and cannabis use disorder in the past year.

\section{Comparison between patients and controls on explicit cannabis-related cognitions}

MANOVA performed in all patients $(n=70)$ and controls $(n=61)$ indicated that patients differed significantly on their explicit cannabis use expectancies from healthy controls $[F(3,127)=5.58, p=0.001$, Wilks' $\left.\lambda=0.88, \eta_{\mathrm{p}}^{2}=0.12\right]$. Relative contributions to this multivariate difference were (in descending order, with structure coefficients in parentheses): negative $(0.87)$; active (0.10); relaxed (0.04). An inspection of the mean scores indicated that patients had higher scores on the negative scale $($ mean $=4.74$, S.D. $=2.35)$ than controls $($ mean $=3.35$, s.D. $=2.07)$.

MANOVA performed in all past and recent users of cannabis (61 patients and 46 controls) also indicated that patients and controls scored significantly different on the explicit scale $[F(3,103)=4.81, p=0.004$, Wilks' $\left.\lambda=0.88, \eta_{\mathrm{p}}^{2}=0.12\right]$, with relative contributions: negative $(0.85)$; active $(0.15)$; relaxed $(-0.03)$. See Fig. $1 a$ for mean scores on the explicit expectancy measure for all past and recent users of cannabis. 
(a)

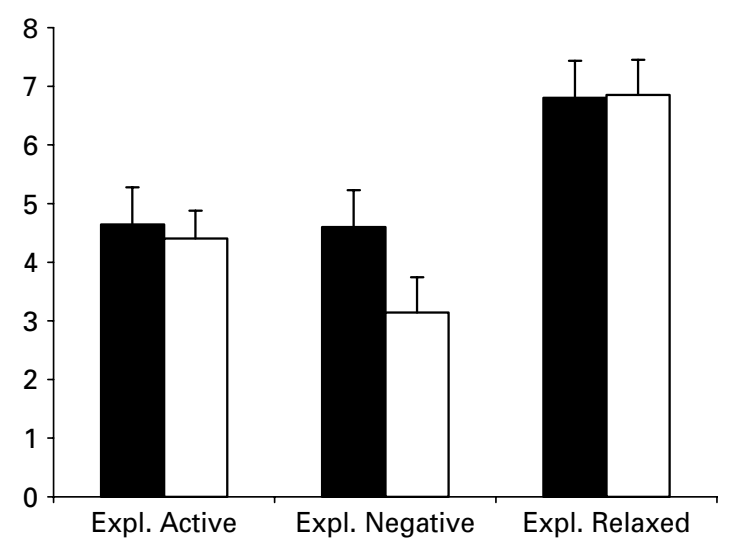

(b)

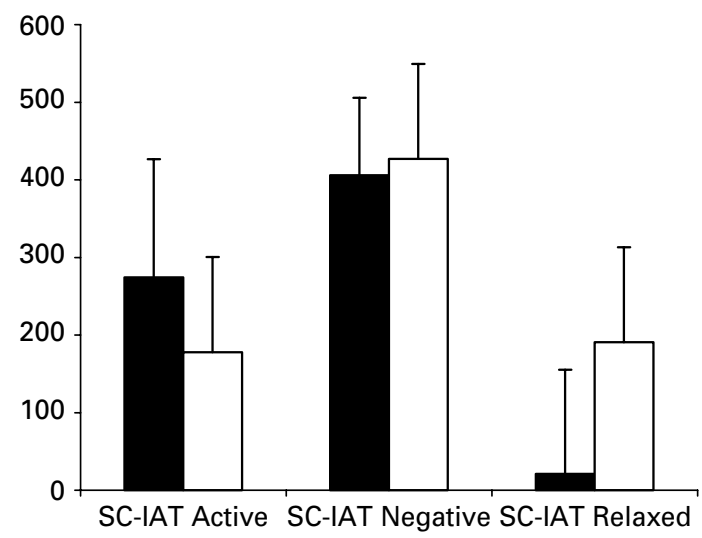

Fig. 1. Means on the explicit and implicit measures in all past and recent cannabis users by participant group. (a) Means on the explicit (visual analogue scale) measures [61 patients (घ) and 46 controls $(\square)$ ]; (b) mean Implicit Association Test effects (D-2SD, ms) separately for each Single Category Implicit Association Test (SC-IAT) in all past and recent cannabis users by participant group [56 patients ( $\mathbf{\square})$ and 44 controls $(\square)]$.

MANOVA performed in the group of recent users (46 patients, 40 controls) and recent frequent users (36 patients, 27 controls) also indicated that patients and controls scored significantly different on the explicit scales [respectively, $F(3,82)=3.39, p=0.02$, Wilks' $\lambda 0.89, \eta_{\mathrm{p}}^{2}=0.11$, and $F(3,59)=3.17, p=0.03$, Wilks' $\left.\lambda 0.86, \eta_{\mathrm{p}}^{2}=0.14\right]$, with highest relative contributions for this multivariate difference on the negative scale. Relative contributions in all recent users: negative (0.83); active $(0.25)$; relaxed $(-0.13)$. Relative contributions in recent frequent users: negative $(0.89)$; relaxed $(-0.19)$; active $(0.14)$.

\section{Comparison between patients and controls on implicit cannabis-related cognitions}

Prior to conducting analysis on the SC-IAT, we detected outliers and excluded them from the dataset: five participants (four patients, one control) were excluded from further analysis because they had a percentage of response errors on the SC-IAT that was $>3$ s.D. from the mean and two participants (one patient and one control) were excluded because more than $10 \%$ of their reaction times were faster than $300 \mathrm{~ms}$ on the SC-IAT (see Greenwald et al. 2003).

MANOVA performed in all patients $(n=65)$ and controls $(n=59)$ indicated that patients did not differ significantly from healthy controls on their implicit cannabis use associations $[F(3,120)=1.16, p=0.327$, Wilks' $\left.\lambda=0.97, \eta_{\mathrm{p}}^{2}=0.03\right]$. Additionally, no significant differences emerged between patients and controls when all past and recent users (56 patients, 44 controls), $p=0.25$, when only recent users (42 patients, 38 controls), $p>0.30$ or when recent frequent users (33 patients, 25 controls), $p>0.80$, were taken into account. See Fig. $1 b$ for mean scores on the SC-IATs for all past and recent users of cannabis.

\section{Factors predicting craving and cannabis use}

Prior to conducting regression analysis, we determined that no participant exceeded Cook's distance $>1$. The regression models were evaluated on the basis of the results of bivariate analyses (see Table 3); only the explicit and implicit variables that were significantly correlated with craving or cannabis use were included in the multiple regression models.

\section{Craving as dependent variable}

Craving was best predicted by the explicit relaxed measure $(\beta=0.25, p=0.017)$, adjusted for the other predictors (see Table 4). The implicit measures (as a group) showed a trend towards significance in the prediction of craving $\left(\Delta R^{2}=0.05, p=0.06\right)$ above and beyond the background variables and explicit measures. Overall, the full model explained $20.9 \%$ of the variance in the total craving score $\left[R^{2}\right.$ adjusted $=$ $0.15, F(7,92)=3.47, p<0.005]$. In subsequent analyses we evaluated a trimmed regression model for craving, which included all (borderline) significant $(p<0.10)$ predictor variables (see Table 5). This overall trimmed regression model was statistically significant $[F(3,96)=6.97, p<0.0005$, explaining $18 \%$ of the variance in craving, $R^{2}$ adjusted $\left.=0.15\right]$. Again, craving was best predicted by the explicit relaxed measure $(\beta=0.31$, $p=0.001$ ), adjusted for the other implicit predictors. The implicit measure of active associations predicted craving borderline significantly $(\beta=0.17, p=0.068)$.

\section{Cannabis use as dependent variable}

Explicit relaxed expectancies significantly predicted cannabis use $\left(\Delta R^{2}=0.21, p<0.0001\right)$ above and beyond 
Table 3. Pearson correlations between explicit expectancies and implicit associations and cannabis use variables in all past and recent cannabis users $(n=100: 56$ patients and 44 controls)

\begin{tabular}{|c|c|c|c|c|c|c|c|c|}
\hline & 1 & 2 & 3 & 4 & 5 & 6 & 7 & 8 \\
\hline 1. Expl Active & - & & & & & & & \\
\hline 2. Expl Negative & $-0.31^{* *}$ & - & & & & & & \\
\hline 3. Expl Relaxed & $0.30^{* *}$ & $-0.43^{* *}$ & - & & & & & \\
\hline 4. SC-IAT Active & 0.13 & -0.01 & 0.09 & - & & & & \\
\hline 5. SC-IAT Negative & -0.03 & 0.12 & $-0.20^{*}$ & 0.01 & - & & & \\
\hline 6. SC-IAT Relaxed & $-0.19^{\#}$ & -0.11 & 0.08 & 0.02 & 0.11 & - & & \\
\hline 7. Craving & $0.26^{* *}$ & 0.11 & $0.36^{* *}$ & $0.20^{*}$ & $-0.22^{*}$ & -0.04 & - & \\
\hline 8. Cannabis use & 0.03 & -0.12 & $0.47^{* *}$ & 0.06 & -0.11 & 0.11 & $0.57^{* *}$ & - \\
\hline
\end{tabular}

Expl Active, explicit positive-arousal cannabis use expectancies; Expl Negative, explicit negative cannabis use expectancies; Expl Relaxed, explicit positive-sedation cannabis use expectancies; SC-IAT, Single Category Implicit Association Test; SC-IAT Active, D (standardized difference score) - 2SD score for the positive-arousal SC-IAT; SC-IAT negative, D - 2SD score for the negative SC-IAT; SC-IAT relaxed, D - 2SD score for the positive-sedation SC-IAT; Craving, total Obsessive Compulsive Drug Use Scale score; Cannabis use, total cannabis joints used in past year in participants who have used cannabis in the past year.

${ }^{*} p \leqslant 0.10,{ }^{*} p<0.05,{ }^{* *} p<0.01$.

Table 4. Summary of hierarchical multivariate regression analysis for variables predicting craving and cannabis use (cross-sectional)

\begin{tabular}{|c|c|c|c|c|c|}
\hline \multirow[b]{2}{*}{ Variable } & \multicolumn{2}{|c|}{ Cumulative } & \multicolumn{3}{|c|}{ Simultaneous } \\
\hline & $R^{2}$ & $\Delta R^{2}$ & $B$ & S.E. $B$ & $B$ \\
\hline \multicolumn{6}{|c|}{$\begin{array}{l}\text { Craving } n=100 \\
\text { (56 patients, } 44 \text { controls) }\end{array}$} \\
\hline Participant group & 0.00 & & 0.02 & 0.03 & 0.07 \\
\hline Education 1 & & & 0.02 & 0.03 & 0.08 \\
\hline Education 2 & 0.02 & 0.02 & 0.03 & 0.04 & 0.08 \\
\hline Expl. Active & & & 0.01 & 0.01 & 0.16 \\
\hline Expl. Relaxed & 0.16 & $0.14^{* *}$ & 0.02 & 0.01 & $0.25^{*}$ \\
\hline SC-IAT Active & & & 0.05 & 0.03 & $0.16^{\#}$ \\
\hline SC-IAT Negative & 0.21 & $0.05^{\#}$ & -0.07 & 0.04 & $-0.17^{\#}$ \\
\hline \multicolumn{6}{|c|}{$\begin{array}{l}\text { Cannabis use } n=78 \\
\text { (41 patients, } 37 \text { controls) }\end{array}$} \\
\hline Participant group & 0.01 & & -0.23 & 0.20 & -0.12 \\
\hline Education 1 & & & 0.14 & 0.25 & 0.07 \\
\hline Education 2 & 0.03 & 0.02 & 0.23 & 0.28 & 0.10 \\
\hline Expl Relaxed & 0.25 & $0.21^{* *}$ & 0.25 & 0.06 & $0.48^{* *}$ \\
\hline
\end{tabular}

Craving, total Obsessive Compulsive Drug Use Scale score; Education 1, lower secondary professional education/intermediate vocational education; Education 2, higher general secondary education/higher vocational education; Expl. Active, explicit positive-arousal cannabis use expectancies; Expl Relaxed, explicit positive-sedation cannabis use expectancies; SC-IAT, Single Target Implicit Association Test; SC-IAT Active, D (standardized difference score) - 2SD score for the positive-arousal SC-IAT; SC-IAT Negative, D - 2SD score for the negative SC-IAT; Cannabis use, total cannabis joints used in past year (in participants who have used cannabis in the past year).

${ }^{\#} p \leqslant 0.10,{ }^{*} p<0.05, * * p<0.01$. 
Table 5. Trimmed regression model for craving

\begin{tabular}{|c|c|c|c|c|c|}
\hline \multirow[b]{2}{*}{ Variable } & \multicolumn{2}{|c|}{ Cumulative } & \multicolumn{3}{|c|}{ Simultaneous } \\
\hline & $R^{2}$ & $\Delta R^{2}$ & $B$ & S.E. $B$ & $B$ \\
\hline \multicolumn{6}{|l|}{$\begin{array}{l}\text { Craving, } n=100 \\
\text { (56 patients, } \\
44 \text { controls) }\end{array}$} \\
\hline Expl Relaxed & $0.13^{* *}$ & & 0.02 & 0.01 & $0.31^{* *}$ \\
\hline SC-IAT Active & 0.16 & $0.03^{\#}$ & 0.05 & 0.03 & $0.17^{\#}$ \\
\hline SC-IAT Negative & 0.18 & 0.02 & -0.06 & 0.04 & -0.16 \\
\hline
\end{tabular}

S.E., Standard error ; SC-IAT, Single Category Implicit Association Test.

${ }^{\#} p \leqslant 0.10, * p<0.05, * * p<0.01$.

the background variables (see Table 4). Overall, the full model explained $24.6 \%$ of the variance in total cannabis joints used in the past year $\left[R^{2}\right.$ adjusted $=$ $0.21, F(4,73)=5.96, p<0.0005]$.

\section{Discussion}

In this study, we found that patients with recent-onset psychotic disorder and controls did not differ in implicit affective cannabis associations. In contrast, patients scored significantly higher on explicit negative cannabis expectancies than healthy controls, irrespective of their level of cannabis use. An explanation for this finding could be that all patients received education in our clinic about how cannabis use can deteriorate symptoms and the course of the disease. Additionally, patients might have experienced more severe negative effects of smoking cannabis. Some evidence for this comes from Green et al. (2004), who found that a larger proportion of individuals with psychosis reported psychotic symptoms as negative effects of cannabis, compared with healthy controls. Peters et al. (in press) found that patients with schizophrenia reported more often than controls to have felt depressed, anxious and suspicious and to have experienced more psychotic symptoms during cannabis intoxication. Additionally, an experimental study showed that patients with schizophrenia, compared with healthy controls, were more sensitive to the cognitive effects of $\Delta^{9}$-THC on learning and recall (d'Souza et al. 2004, 2005). However, Henquet et al. (2006) did not replicate this finding, but found that differential $\Delta^{9}$-THC sensitivity was restricted to subjects homozygous for the catechol-O-methyltransferase (COMT Val ${ }^{158} \mathrm{Met}$ ) valine allele and that this was, in part, conditional on psychometric psychosis liability.

Both patients and controls had strong explicit relaxed outcome expectancies of cannabis use. Relaxation is a consistently reported effect of cannabis in people with and without psychosis (Green et al. 2003; Pencer \& Addington, 2008; Dekker et al. 2009). Relaxation might be an important motivator for use of cannabis in both participant groups. Our regression analysis showed that the explicit relaxed subscale was the strongest predictor for craving and level of cannabis use. Ames et al. (2007) also found that explicit relaxed expectancies strongly predicted cannabis use in a high school population. Possibly, people who experience relaxing effects may eventually smoke more cannabis and consequently develop more craving for cannabis.

Another notable association among patients and controls was the strong implicit negative association towards cannabis. This finding is in line with previous research on implicit associations towards alcohol use (Wiers et al. 2002, 2005; De Houwer et al. 2004) and towards smoking (Swanson et al. 2001). However, another cannabis IAT study (Field et al. 2004) found that negative associations were present in non-users of cannabis, but not in users of cannabis. Usage of a different IAT may explain differences between their findings and ours: Field et al. (2004) used a bipolar IAT, where positive associations were measured relative to negative associations.

There are some plausible explanations for the strong implicit negative cannabis associations. It might be that users of cannabis engage in a behaviour they do not implicitly like and go along with their cannabis use behaviour more on the explicit rather than on the implicit level. Other explanations have to do with concerns about the validity of the IAT effect. One concern is that strong negative implicit associations may partly reflect general associations that are present in a culture instead of someone's personal associations (Karpinski \& Hilton, 2001). Houben \& Wiers $(2007 a, b)$ examined this by using personalized alcohol-IATs (where the labels 'positive' and 'negative' were replaced by the labels 'I like' or 'I dislike'). They found implicit positive associations towards alcohol and weaker negative attitudes towards alcohol, which is in line with the hypothesis that the standard alcohol-IAT may to some extent reflect negative general associations with alcohol. However, in one of their studies $(2007 b)$, the personalized IAT did not show evidence for implicit positive attitudes towards alcohol.

Another concern is that the IAT measures associations at the level of the category and not at the level of the individual words from this category (De Houwer, 2001). People might associate 'cannabis' (the category label in our study) with negative consequences because of usage of this word in the media and associate words such as 'weed' or 'stoned' with more pleasant effects. Houben \& Wiers (2006a) found that this 'label 
effect' may indeed play a role in the IAT; however, in all IAT versions they found strong negative alcohol associations, suggesting they reflect something 'real' in memory rather than an IAT artefact. Finally, it has been argued that IAT effects could reflect nonassociative factors based on salience, rather than on implicit associations (Rothermund \& Wentura, 2004). Salience could facilitate IAT performance. When two salient categories have to be categorized under the same key, this will be easier than categorizing under two different keys. A previous alcohol-IAT study showed that this salience asymmetry could only partly explain the results found for the negative associations and not at all for the positive and arousal associations (Houben \& Wiers, 2006b). Additionally, many studies (e.g. Ames et al. 2007; Thush \& Wiers, 2007; Thush et al. 2007) show that the IAT predicts behaviour and it correlates with explicit measures on less controversial themes (Hofmann et al. 2005), implying that the IAT encompasses personal associations, at least in part. Also, in our study implicit associations correlated significantly with craving, so extra-personal contamination is not likely to completely account for the effects with the cannabis SC-IAT.

In the present study, there was a trend for implicit active associations to predict craving. Wiers et al. (2002) hypothesized that their finding of implicit arousal associations in heavy drinkers is in line with the incentive-sensitization theory (Robinson \& Berridge, 1993), according to which addictive behaviours are related more to 'wanting' (sensitized arousal) than to liking of substances. This sensitized arousal or intensively wanting substances may be transformed into craving (Robinson \& Berridge, 1993) and thereby explain our finding.

As opposed to craving, cannabis use was unrelated to implicit associations. This is in contrast with another cannabis IAT study (Ames et al. 2007), which revealed that implicit excited associations predicted cannabis use. Differences between the present study and previous findings of Ames et al. (2007) might be attributed to differences in the study population, outcome variables and differences in the IATs used.

In summary, there is reason to doubt the validity of the strong negative substance-associations found here and in many other studies (extra-personal associations, saliency effects), but the active and relaxation associations appear to be more valid and related to meaningful other constructs including craving.

\section{Limitations and strengths}

A limitation of this study is that the percentages of THC in CBD in cannabis products used by the participants were unknown. THC is thought to give psychotomimetic effects (d'Souza et al. 2004) and CBD has anxiolytic and antipsychotic properties (Leweke et al. 2000; Zuardi et al. 2006). Although it is likely that the variation of cannabis ingredients was equally distributed among patients and controls, we do not know the different contributions of THC and CBD to explicit and implicit cannabis associations.

Another limitation is that we did not have selfreports on cannabis intoxication at the time of testing and we did not use urinary screens to confirm that subjects were not intoxicated at the time of testing. To control for possible slower reaction times and response errors due to cannabis intoxication, we used the D2SD reaction time measure (Greenwald et al. 2003), which is not influenced by differences in response speed between participants, and we excluded IAT data of five participants who had a percentage of response errors on the SC-IAT that were $>3$ S.D. from the mean.

Finally, our study had a cross-sectional nature and many of the observed relationships were relatively weak. A prospective study examining relationships between cannabis associations and cannabis use variables might overcome these limitations.

However, this study does provide additional information for the role of cannabis-related cognitions in patients with recent-onset schizophrenia spectrum disorders. Strengths of this study were that we had a relatively large sample of recent-onset schizophrenia patients and a matched control group. To our knowledge, this is the first study that assessed implicit cannabis associations in patients with psychosis and controls.

\section{Conclusions and practical implications}

Our findings indicate that patients suffering from schizophrenia have associations towards cannabis similar to controls, but they have stronger negative explicit cannabis associations. The finding of strong negative implicit associations towards cannabis in both patients and controls could imply that they engage in behaviour that they do not implicitly like. Explicit relaxed associations towards cannabis were the strongest predictor of cannabis use and craving, which might imply that the perceived relaxing effects of cannabis is an important mediator in the continuation of cannabis use. Therefore, intervention and prevention strategies aimed at reducing cannabis use should target the explicit cognitions related to the relaxing effects of cannabis that may be due to the CBD compound in cannabis.

Further, because implicit positive arousal cognitions were associated with craving, an important intervention would be to challenge these cognitions in 
order to prevent relapse into cannabis use. Although researchers have begun to study whether it is possible to change implicit alcohol associations (Wiers et al. 2008), future research is needed to indicate how automatic cannabis associations could be changed and, if so, how this effects the use of cannabis.

\section{Appendix. Implicit Association Test word stimuli (translated from Dutch)}

\begin{tabular}{lc}
\hline $\begin{array}{c}\text { Positive arousal stimuli } \\
\text { (active words) }\end{array}$ & $\begin{array}{c}\text { Neutral stimuli } \\
\text { (neutral words) }\end{array}$ \\
creative & indefinite \\
energetic & general \\
cheerful & usual \\
motivated & standard \\
talkative & impartial \\
Positive sedation stimuli & Neutral stimuli \\
(relaxed words) & (neutral words) \\
relaxed & accompanying \\
calming & preceding \\
contented & supplementary \\
comforting & frequent \\
reassuring & additional \\
Negative stimuli & Neutral stimuli \\
(negative words) & (neutral words) \\
miserable & central \\
suspicious & daily \\
listless & middle \\
anxious & common \\
confused & customary \\
Target & \\
(cannabis words) & \\
weed & \\
hash & \\
cannabis & \\
stoned & \\
blow & \\
\hline & \\
\hline
\end{tabular}

\section{Acknowledgements}

This study was partly supported by grants from the Dutch Health Research and Development Council (ZON) nr 10.000.1001.

\section{Declaration of Interest}

None.

\section{References}

Addington J, Addington D (2007). Patterns, predictors and impact of substance use in early psychosis: a longitudinal study. Acta Psychiatrica Scandinavica 115, 304-309.
Addington J, Duchak V (1997). Reasons for substance use in schizophrenia. Acta Psychiatrica Scandinavica 96, 329-333.

Ames SL, Grenard JL, Thush C, Sussman S, Wiers RW, Stacy AW (2007). Comparison of indirect assessments of association as predictors of marijuana use among at-risk adolescents. Experimental and Clinical Psychopharmacology 15, 204-218.

APA (1994). Diagnostic and Statistical Manual of Mental Disorders, 4th edn. American Psychiatric Association: Washington DC.

Barnes TR, Mutsatsa SH, Hutton SB, Watt HC, Joyce EM (2006). Comorbid substance use and age at onset of schizophrenia. British Journal of Psychiatry 188, 237-242.

Barnett JH, Werners U, Secher SM, Hill KE, Brazil R, Masson K, Pernet DE, Kirkbride JB, Murray GK, Bullmore ET, Jones PB (2007). Substance use in a population-based clinical sample of people with first-episode psychosis. British Journal of Psychiatry 190, 515-520.

Cantwell R, Brewin J, Glazebrook C, Dalkin T, Fox R, Medley I, Harrison G (1999). Prevalence of substance misuse in first-episode psychosis. British Journal Psychiatry 174, 150-153.

De Haan L, Linszen DH, Lenior ME, De Win ED, Gorsira R (2003). Duration of untreated psychosis and outcome of schizophrenia: delay in intensive psychosocial treatment versus delay in treatment with antipsychotic medication. Schizophrenia Bulletin 29, 341-348.

De Houwer J (2001). A structural and process analysis of the Implicit Association Test. Journal of Experimental Social Psychology 37, 443-451.

De Houwer J, Crombez G, Koster EH, De Beul N (2004). Implicit alcohol-related cognitions in a clinical sample of heavy drinkers. Journal of Behavior Therapy and Experimental Psychiatry 35, 275-286.

Dekker N, De Haan L, Van den Berg S, De Gier M, Becker H, Linszen DH (2008). Cessation of cannabis use by patients with recent-onset schizophrenia and related disorders. Psychopharmacology Bulletin 4, 142-153.

Dekker N, Linszen DH, De Haan L (2009). Reasons for cannabis use and effects of cannabis use as reported by patients with psychotic disorders. Psychopathology $\mathbf{4 2}$, 350-360.

Dixon L, Haas G, Weiden P (1990). Acute effects of drug abuse in schizophrenic patients: clinical observations and patients' self-report. Schizophrenia Bulletin 16, 69-79.

d'Souza DC, Abi-Saab WM, Madonick S, Forselius-Bielen K, Doersch A, Braley G, Gueorguieva R, Cooper TB, Krystal JH (2005). Delta-9-tetrahydrocannabinol effects in schizophrenia: implications for cognition, psychosis, and addiction. Biological Psychiatry 57, 594-608.

d'Souza DC, Perry E, Macdougall L, Ammerman Y, Cooper T, Wu YT, Braley G, Gueorguieva R, Krystal JH (2004). The psychotomimetic effects of intravenous delta-9tetrahydrocannabinol in healthy individuals: implications for psychosis. Neuropsychopharmacology 29, 1558-1572.

Field M, Mogg K, Bradley BP (2004). Cognitive bias and drug craving in recreational cannabis users. Drug Alcohol Dependence 74, 105-111. 
Fowler IL, Carr VJ, Carter NT, Lewin TJ (1998). Patterns of current and lifetime substance use in schizophrenia. Schizophrenia Bulletin 24, 443-455.

Franken IH (2003). Drug craving and addiction: integrating psychological and neuropsychopharmacological approaches. Progress in Neuro-psychopharmacology $\mathcal{E}$ Biological Psychiatry 27, 563-579.

Franken IH, Hendriksen VM, Van den Brink W (2002). Initial validation of two opiate craving questionnaires the obsessive compulsive drug use scale and the desires for drug questionnaire. Addictive Behaviors 27, 675-685.

Goldman MS, Darkes J (2004). Alcohol expectancy multiaxial assessment: a memory network-based approach. Psychological Assessment 16, 4-15.

Green B, Kavanagh D, Young R (2003). Being stoned: a review of self-reported cannabis effects. Drug and Alcohol Review 22, 453-460.

Green B, Kavanagh DJ, Young RM (2004). Reasons for cannabis use in men with and without psychosis. Drug and Alcohol Review 23, 445-453.

Greenwald AG, Banaji MR (1995). Implicit social cognition: attitudes, self-esteem, and stereotypes. Psychological Review 102, 4-27.

Greenwald AG, McGhee DE, Schwartz JL (1998). Measuring individual differences in implicit cognition: the implicit association test. Journal of Personality and Social Psychology 74, 1464-1480.

Greenwald AG, Nosek BA, Banaji MR (2003). Understanding and using the implicit association test: I. An improved scoring algorithm. Journal of Personality and Social Psychology 85, 197-216.

Hambrecht M, Hafner H (1996). Substance abuse and the onset of schizophrenia. Biological Psychiatry 40, 1155-1163.

Henquet C, Rosa A, Krabbendam L, Papiol S, Fananás L, Drukker M, Ramaekers JG, Van Os J (2006). An experimental study of catechol-o-methyltransferase Val158Met moderation of delta-9-tetrahydrocannabinolinduced effects on psychosis and cognition.

Neuropsychopharmacology 31, 2748-2757.

Hides L, Kavanagh DJ, Dawe S, Young RM (2008). The influence of cannabis use expectancies on cannabis use and psychotic symptoms in psychosis. Drug Alcohol Review, $1-7$.

Hofmann W, Gawronski B, Gschwendner T, Le H, Schmitt M (2005). A meta-analysis on the correlation between the implicit association test and explicit self-report measures. Personality and Social Psychology Bulletin 31, 1369-1385.

Holtgraves T (2004). Social desirability and self-reports: testing models of socially desirable responding. Personality and Social Psychology Bulletin 30, 161-172.

Houben K, Wiers RW (2006a). Assessing implicit alcohol associations with the Implicit Association Test: fact or artifact? Addictive Behaviors 31, 1346-1362.

Houben K, Wiers RW (2006b). A test of the salience asymmetry interpretation of the alcohol-IAT. Experimental Psychology 53, 292-300.

Houben K, Wiers RW (2007a). Are drinkers implicitly positive about drinking alcohol? Personalizing the
alcohol-IAT to reduce negative extrapersonal contamination. Alcohol \& Alcoholism 42, 301-307.

Houben K, Wiers RW (2007b). Personalizing the alcohol-IAT with individualized stimuli : relationship with drinking behavior and drinking-related problems. Addictive Behaviors 32, 2852-2864.

Huberty CJ, Morris JD (1989). Multivariate analysis versus multiple univariate analysis. Psychological Bulletin 105, 302-208.

Kahneman D (2003). A perspective on judgment and choice: mapping bounded rationality. American Psychologist 58, 697-720.

Karpinski A, Hilton JL (2001). Attitudes and the Implicit Association Test. Journal of Personality and Social Psychology 81, 774-788.

Karpinski A, Steinman RB (2006). The single category implicit association test as a measure of implicit social cognition. Journal of Personality and Social Psychology 91, 16-32.

Leweke FM, Schneider U, Radwan M, Schmidt E, Emrich HM (2000). Different effects of nabilone and cannabidiol in binocular depth inversion in man. Pharmacology Biochemistry and Behaviour 66, 175-181.

Linszen DH, Dingemans PM, Lenior ME (1994). Cannabis abuse and the course of recent-onset schizophrenic disorders. Archives General Psychiatry 51, 273-279.

McCusker CG (2001). Cognitive biases and addiction: an evolution in theory and method. Addiction 96, 47-56.

Mueser KT, Nishith P, Tracy JI, DeGirolamo J, Molinaro M (1995). Expectations and motives for substance use in schizophrenia. Schizophrenia Bulletin 21, 367-378.

Niesink R, Rigter S, Hoek J, Goldschmidt H (2007). THC-concentraties in wiet, nederwiet en hasj in Nederlandse coffeeshops (2006-2007). Trimbos-instituut, Utrecht: The Netherlands.

Pencer A, Addington J (2008). Reasons for using substances in adolescents with and without psychosis. Early Intervention in Psychiatry 2, 42-44.

Peters BD, De Koning P, Dingemans P, Becker H, Linszen DH, De Haan L (in press). Subjective effects of cannabis before the first psychotic episode. Australian and New Zealand Journal of Psychiatry.

Robinson TE, Berridge KC (1993). The neural basis of drug craving: an incentive-sensitization theory of addiction. Brain Research Reviews 18, 247-291.

Rothermund K, Wentura D (2004). Underlying processes in the implicit association test: dissociating salience from associations. Journal of Experimental Psychology: General 133, 139-165.

Schofield D, Tennant C, Nash L, Degenhardt L, Cornish A, Hobbs C, Brennan G (2006). Reasons for cannabis use in psychosis. Australian and New Zealand Journal of Psychiatry 40, 570-574.

Spencer C, Castle D, Michie PT (2002). Motivations that maintain substance use among individuals with psychotic disorders. Schizophrenia Bulletin 28, 233-247.

Stacy AW (1997). Memory activation and expectancy as prospective predictors of alcohol and marijuana use. Journal of Abnormal Psychology 106, 61-73. 
Swanson JE, Rudman LA, Greenwald AG (2001). Using the Implicit Association Test to investigate attitude-behaviour consistency for stigmatised behaviour. Cognition and Emotion 15, 207-230.

Thush C, Wiers RW (2007). Explicit and implicit alcohol-related cognitions and the prediction of future drinking in adolescents. Addictive Behaviors 32, 1367-1383.

Thush C, Wiers RW, Ames SL, Grenard JL, Sussman S, Stacy AW (2007). Apples and oranges? Comparing indirect measures of alcohol-related cognition predicting alcohol use in at-risk adolescents. Psychology of Addictive Behaviors 21, 587-591.

Van Mastrigt S, Addington J, Addington D (2004). Substance misuse at presentation to an early psychosis program. Social Psychiatry and Psychiatric Epidemiology 39, 69-72.

Wade D, Harrigan S, Edwards J, Burgess PM, Whelan G, McGorry PD (2006). Substance misuse in first-episode psychosis: 15-month prospective follow-up study. British Journal Psychiatry 189, 229-234.

WHO (1994). Composite International Diagnostic Interview: Core Version 2.1. World Health Organization: Geneva, Switzerland.

Wiers RW (2008). Alcohol and drug expectancies as anticipated changes in affect: negative reinforcement is not sedation. Substance Use \& Misuse 43, 429-444.

Wiers RW, Bartholow BD, Van den Wildenberg WE, Thush C, Engels RC, Sher KJ, Grenard J, Ames SL, Stacy AW (2007a). Automatic and controlled processes and the development of addictive behaviors in adolescents : a review and a model. Pharmacology Biochemistry and Behavior 86, 263-283.

Wiers RW, Houben K, De Kraker J (2007b). Implicit cocaine associations in active cocaine users and controls. Addictive Behaviors 32, 1284-1289.

Wiers RW, Schoenmakers T, Houben K, Thush C, Fadardi JS, Cox WM (2008). Can problematic alcohol use be trained away? New behavioural treatments aimed at changing and moderating implicit cognitive processes in alcohol abuse. In Identification and Treatment of Alcohol Dependency (ed. C. R. Martin), chapter 15, pp. 185-205. M\&K Publishing: Keswick, UK.

Wiers RW, Van de Luitgaarden, Van den Wildenberg, Smulders FT (2005). Challenging implicit and explicit alcohol-related cognitions in young heavy drinkers. Addiction 100, 806-819.

Wiers RW, Van Woerden N, Smulders FT, De Jong PJ (2002). Implicit and explicit alcohol-related cognitions in heavy and light drinkers. Journal of Abnormal Psychology 111, 648-658.

Wilson TD, Lindsey S, Schooler TY (2000). A model of dual attitudes. Psychological Review 107, 101-126.

Zammit S, Moore TH, Lingford-Hughes A, Barnes TR, Jones PB, Burke M, Lewis G (2008). Effects of cannabis use on outcomes of psychotic disorders: systematic review, British Journal of Psychiatry 193, 357-363.

Zuardi AW, Crippa JAS, Hallak JEC, Moreira FA, Guimarães FS (2006). Cannabidiol, a cannabis sativa constituent, as an antipsychotic drug. Brazilian Journal of Medical and Biological Research 39, 421-429. 